\title{
Local structure of $\mathrm{Pt}$ and $\mathrm{Pd}$ ions in $\mathrm{Ce}_{1-x} \mathrm{Ti}_{x} \mathrm{O}_{2}$ : X-ray diffraction, x-ray photoelectron spectroscopy, and extended $\mathrm{x}$-ray absorption fine structure
}

\author{
Tinku Baidya, ${ }_{4}^{1}$ K. R. Priolkar, ${ }^{2}$ P. R. Sarode,${ }^{2}$ M. S. Hegde, ${ }^{1, a)}$ K. Asakura, ${ }^{3}$ G. Tateno, ${ }^{4}$ \\ and Y. Koike \\ ${ }^{1}$ Solid State and Structural Chemistry Unit, Indian Institute of Science, Bangalore 560012, India \\ ${ }^{2}$ Department of Physics, Goa University, Taleigao Plateau, Goa 403206, India \\ ${ }^{3}$ Catalysis Research Centre, Hokkaido University, Sapporo 001-0021, Japan \\ ${ }^{4}$ Photon Factory, Tsukuba-shi, Ibaraki-ken 305-0801, Japan
}

(Received 29 November 2007; accepted 11 January 2008; published online 28 March 2008)

\begin{abstract}
$\mathrm{Ce}_{1-x-y} \mathrm{Ti}_{x} \mathrm{Pt}_{y} \mathrm{O}_{2-\delta}(x=0.15 ; y=0.01)$ and $\mathrm{Ce}_{1-x-y} \mathrm{Ti}_{x} \mathrm{Pd}_{y} \mathrm{O}_{2-\delta}(x=0.25 ; y=0.02$ and 0.05$)$ are found to be good CO oxidation catalysts [T. Baidya et al., J. Phys. Chem. B 110, 5262 (2006); T. Baidya et al., J. Phys. Chem. C 111, 830 (2007)]. A detailed structural study of these compounds has been carried out by extended $\mathrm{x}$-ray absorption fine structure along with $\mathrm{x}$-ray diffraction and $\mathrm{x}$-ray photoelectron spectroscopy. The gross cubic fluorite structure of $\mathrm{CeO}_{2}$ is retained in the mixed oxides. Oxide ion sublattice around $\mathrm{Ti}$ as well as $\mathrm{Pt}$ and $\mathrm{Pd}$ ions is destabilized in the solid solution. Instead of ideal eight coordinations, $\mathrm{Ti}, \mathrm{Pd}$, and $\mathrm{Pt}$ ions have $4+3,4+3$, and $3+4$ coordinations creating long and short bonds. The long Ti-O, Pd-O, and $\mathrm{Pt}-\mathrm{O}$ bonds are $\sim 2.47 \AA$ ( $2.63 \AA$ for $\mathrm{Pt}-\mathrm{O})$ which are much higher than average $\mathrm{Ce}-\mathrm{O}$ bonds of $2.34 \AA$. (C) 2008 American Institute of Physics. [DOI: 10.1063/1.2841365]
\end{abstract}

\section{INTRODUCTION}

Ionically dispersed $\mathrm{Pd}, \mathrm{Cu}, \mathrm{Pt}$, and $\mathrm{Rh}$ in $\mathrm{CeO}_{2}$ have shown higher catalytic activity compared to the impregnated catalysts. ${ }^{1-6}$ Interaction of noble metal ions with $\mathrm{CeO}_{2}$ support has played a crucial role in redox reactions bringing down the catalytic reaction temperature and decrease in activation energy. Oxygen storage capacity (OSC), a well known property of $\mathrm{CeO}_{2}$, acts as a buffer medium of oxygen required in redox reaction. Noble metal ion substitution in $\mathrm{CeO}_{2}$ promotes reduction of the support at much lower temperature. However, the amount of lattice oxygen taking part in the redox reaction is small in pure $\mathrm{CeO}_{2}$.

Modification of $\mathrm{CeO}_{2}$ by the substitution of smaller cation like $\mathrm{Zr}$ or Ti has shown enhancement of OSC. $\mathrm{Zr}$ substitution in $\mathrm{CeO}_{2}$ forming $\mathrm{Ce}_{1-x} \mathrm{Zr}_{x} \mathrm{O}_{2}$ solid solution has been extensively studied in the literature. ${ }^{7-11} \mathrm{Ti}$ ion substitution in $\mathrm{CeO}_{2}$ forming $\mathrm{Ce}_{1-x} \mathrm{Ti}_{x} \mathrm{O}_{2}$ solid solution has been reported by us recently. ${ }^{12}$ In this oxide both $\mathrm{Ce}$ and $\mathrm{Ti}$ have four long + four short bond with oxygen compared to ideal eight coordinations in $\mathrm{CeO}_{2} \cdot{ }^{13}$ Since both $\mathrm{Ti}$ and $\mathrm{Ce}$ ions are reducible, higher catalytic activity was observed in the presence of Pt and Pd ion. ${ }^{12,14}$ Therefore, understanding of the local structure of Pt and Pd ions in this mixed oxide is important. However, at 1-2 at. \% Pt or Pd ion substitution in $\mathrm{Ce}_{1-x} \mathrm{Ti}_{x} \mathrm{O}_{2}$, it is often difficult to ascertain the structure by $\mathrm{x}$-ray diffraction (XRD) alone.

Here we report local structure of Pt and Pd ions substituted in $\mathrm{Ce}_{1-x} \mathrm{Ti}_{x} \mathrm{O}_{2}$ by a detailed XRD, x-ray photoelectron spectroscopy (XPS), and extended x-ray absorption fine structure EXAFS study.

\footnotetext{
${ }^{a}$ Author to whom correspondence should be addressed. Electronic mail: mshegde@sscu.iisc.ernet.in. Tel.: +91-80-2293-2614. FAX: +91-802360-1310.
}

\section{EXPERIMENTAL SECTION}

1 at. $\% \mathrm{Pt} / \mathrm{Ce}_{0.85} \mathrm{Ti}_{0.15} \mathrm{O}_{2}$ was prepared by the solution combustion method taking $\left(\mathrm{NH}_{4}\right)_{2} \mathrm{Ce}\left(\mathrm{NO}_{3}\right)_{6} \cdot 6 \mathrm{H}_{2} \mathrm{O}$, $\mathrm{Pt}\left(\mathrm{NH}_{3}\right)_{3}\left(\mathrm{NO}_{3}\right)_{2}$ (ABCR, France), $\mathrm{TiO}\left(\mathrm{NO}_{3}\right)_{2}$, and glycine in the mole ratio $0.8415: 0.01: 0.1485: 2: 2.42$. In a typical preparation, $\quad 3 \mathrm{~g} \quad\left(\mathrm{NH}_{4}\right)_{2} \mathrm{Ce}\left(\mathrm{NO}_{3}\right)_{6} \cdot 6 \mathrm{H}_{2} \mathrm{O}, \quad 0.0252 \mathrm{~g}$ $\operatorname{Pt}\left(\mathrm{NH}_{3}\right)_{4}\left(\mathrm{NO}_{3}\right)_{2}, 0.1823 \mathrm{~g} \mathrm{TiO}\left(\mathrm{NO}_{3}\right)_{2}$ (in solution), and $1.1814 \mathrm{~g}$ glycine were taken in a $300 \mathrm{ml}$ Pyrex dish. $\mathrm{TiO}\left(\mathrm{NO}_{3}\right)_{2}$ is prepared from $\mathrm{TiCl}_{4}$ and the detailed procedure has been published somewhere else. ${ }^{12}$

$\mathrm{Ce}_{0.73} \mathrm{Ti}_{0.25} \mathrm{Pd}_{0.02} \mathrm{O}_{2-\delta}$ was prepared by solution combustion method taking $\left(\mathrm{NH}_{4}\right)_{2} \mathrm{Ce}\left(\mathrm{NO}_{3}\right)_{6}, \mathrm{PdCl} 2, \mathrm{TiO}\left(\mathrm{NO}_{3}\right)_{2}$ (in solution), and glycine in the molar ratio 0.73:0.02:0.0.25:2.42. For usual preparation, $5 \mathrm{~g}$ $\left(\mathrm{NH}_{4}\right)_{2} \mathrm{Ce}\left(\mathrm{NO}_{3}\right)_{6}, 0.586 \mathrm{~g} \mathrm{TiO}\left(\mathrm{NO}_{3}\right)_{2}, 0.044 \mathrm{~g} \mathrm{PdCl}_{2}$, and $2.08 \mathrm{~g} \mathrm{C}_{2} \mathrm{H}_{5} \mathrm{NO}_{2}$ were taken. The solution is heated in the furnace at $350{ }^{\circ} \mathrm{C}$ which gives product as described in the earlier study. ${ }^{14}$

XRD data of all the mixed oxides and the Pt-substituted oxides were recorded in a Philips X'Pert diffractometer at a scan rate of $0.5 \mathrm{deg} \mathrm{min}^{-1}$ with $0.02 \mathrm{deg}$ step size in the $2 \theta$ range between 20 and $100 \mathrm{deg}$. The refinement was done using FULLPROF-FP2K program ${ }^{15}$ varying 17 parameters, such as overall scale factor and background parameters, along with oxygen occupancy.

XPS spectra of the prepared compounds were recorded in an ESCA-3 Mark II spectrometer (VG Scientific Ltd., England) using $\mathrm{Al} K_{\alpha}$ radiation $(1486.6 \mathrm{eV})$. Binding energies were calibrated with respect to $\mathrm{C}(1 s)$ at $285 \mathrm{eV}$ with a precision of $\pm 0.1 \mathrm{eV}$. For XPS analysis the power samples were made into $0.5 \mathrm{~mm}$ thick, $8 \mathrm{~mm}$ diameter pellets and placed into an ultrahigh vacuum chamber at $10^{-9}$ Torr hous- 
ing the analyzer. The obtained spectra were curve fitted with Gaussian peaks after subtracting a linear background.

Ti $K$, Pt $L_{\text {III }}$, and Pd $K$ edge EXAFS spectra in catalyst and reference samples were recorded at room temperature in the transmission mode with $\mathrm{Si}(311)$ and $\mathrm{Si}(111)$ doublecrystal monochromators at NW10A and BL9A beamlines, respectively, at Photon Factory, Japan. ${ }^{16,17}$ EXAFS was scanned from 4.7 to $5.6 \mathrm{keV}$, from 11 to $12 \mathrm{keV}$ for $\mathrm{Pt}$ EXAFS, and from 24.2 to $25.6 \mathrm{keV}$ for Pd EXAFS spectra. The photon energy was calibrated for each scan with the first inflection point of the absorption edge in respective metal foil. Both the incident $\left(I_{0}\right)$ and transmitted $(I)$ synchrotron beam intensities were measured simultaneously using ionization chamber filled with appropriate gases. The absorbers were made by pressing the fine powder samples into pellets of $10 \mathrm{~mm}$ diameter with boron nitride. To avoid the sample thickness effect, the total $\mu x$ was restricted to a value $\leqslant 3$ by adjusting the thickness of the absorber pellet where $\mu$ is the absorption coefficient and $x$ is the sample thickness. ${ }^{18}$

EXAFS data analysis was done using IFEFFIT program. The value of amplitude reduction factor $\left(S_{0}^{2}\right)$ is deduced from the EXAFS spectra of respective metals with known crystal structural data. ${ }^{19}$ The theoretical calculation of backscattering amplitude and phase shift functions is obtained by using FEFT (6.01) program. ${ }^{20}$ The experimental EXAFS data were fitted with the theoretical EXAFS function using FEFFIT program. ${ }^{21}$

\section{RESULTS AND DISCUSSION}

\section{XRD study}

XRD was carried out to see whether platinum ions are substituted into the $\mathrm{Ce}_{0.85} \mathrm{Ti}_{0.15} \mathrm{O}_{2}$ matrix in $\mathrm{Pt} / \mathrm{Ce}_{0.85} \mathrm{Ti}_{0.15} \mathrm{O}_{2}$ catalyst. Figure 1(a) shows the XRD pattern of as-prepared 1 at. $\% \mathrm{Pt} / \mathrm{Ce}_{0.85} \mathrm{Ti}_{0.15} \mathrm{O}_{2}$ and 1 at. \% Pt impregnated over $\mathrm{Ce}_{0.85} \mathrm{Ti}_{0.15} \mathrm{O}_{2}$ with ten times enlarged in the $Y$ scale. The pattern can be indexed to the fluorite structure. Observed, calculated, and difference XRD patterns of 1 at. $\%$ $\mathrm{Pt} / \mathrm{Ce}_{0.85} \mathrm{Ti}_{0.15} \mathrm{O}_{2}$ are shown in Fig. 1(b). The $R_{\text {Bragg }}, R$ factor, and $\chi^{2}$ values are $1.75,1.81$, and 1.04 , respectively. Keeping all the parameters the same and $\mathrm{Pt}$ ion occupancy equal to $0.0, R_{\mathrm{Bragg}}, R_{F}$, and $\chi^{2}$ were $2.25,1.64$, and 1.15 , respectively. The increase in $R$ factors is significant. This test confirms Pt ion substitution for Ti/Ce sites in the lattice. Therefore, the present model which considers Pt ion substitution at $\mathrm{Ce}^{4+}$ site in $\mathrm{Ce}_{1-x} \mathrm{Ti}_{x} \mathrm{O}_{2}$ lattice is possible. The lattice parameter of $\mathrm{Ce}_{0.85} \mathrm{Ti}_{0.15} \mathrm{O}_{2}$ is 5.4032(2) $\AA$ and in the 1 at. \% Pt ion substituted $\mathrm{Ce}_{0.85} \mathrm{Ti}_{0.15} \mathrm{O}_{2}$, lattice parameter changes to 5.4052(3) A. There are no impurity peaks due to the presence of platinum metal or oxides. This is further confirmed by recording 1 at. \% Pt impregnated over $\mathrm{Ce}_{0.85} \mathrm{Ti}_{0.15} \mathrm{O}_{2}$ where intense $\mathrm{Pt}(111)$ peak is observed. In the impregnated compound $\mathrm{Pt}(111)$ peak is clearly observed, as indicated in Fig. 1(a).

$1 \%$ Pt-substituted catalyst was reduced in $5 \% \mathrm{H}_{2} / \mathrm{Ar}$ gas at $300{ }^{\circ} \mathrm{C}$ for $1 \mathrm{~h}$. Color changed from gray to black. Figure 2 shows the XRD pattern of the reduced sample with magnification in the $Y$ scale. $\mathrm{Pt}(111)$ peak at $2 \theta=39.8$ is not observed. This shows that short duration reduction does not
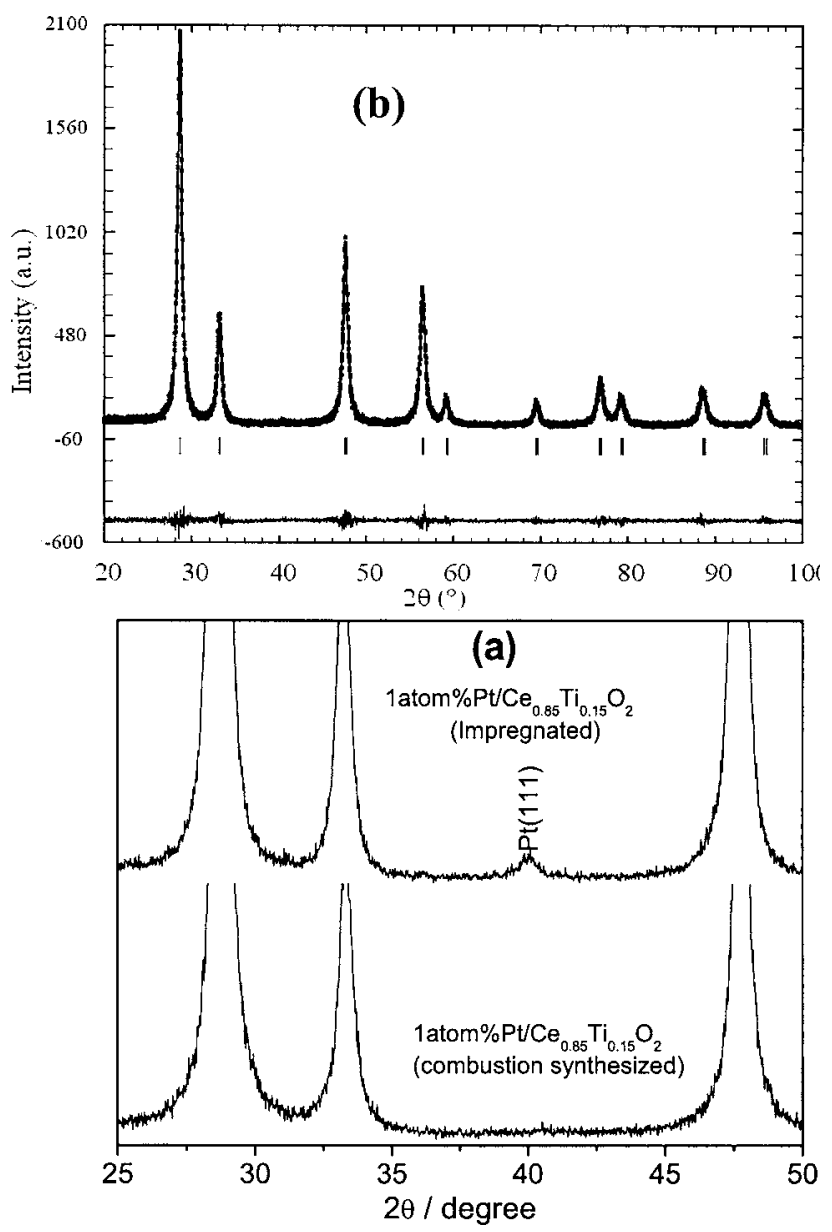

FIG. 1. (a) Ten times enlarged XRD pattern of 1 at. $\% \mathrm{Pt} / \mathrm{Ce}_{0.85} \mathrm{Ti}_{0.15} \mathrm{O}_{2}$ and 1 at. $\% \mathrm{Pt} / \mathrm{Ce}_{0.85} \mathrm{Ti}_{0.15} \mathrm{O}_{2}$ (impregnated) and (b) Rietveld refined 1 at. \% $\mathrm{Pt} / \mathrm{Ce}_{0.85} \mathrm{Ti}_{0.15} \mathrm{O}_{2}$

allow Pt metal atoms sintering to metal particles. We believe that atoms are retained in the same sites as in the unreduced samples. A similar experiment has been reported in the literature as an evidence for Pd ion substitution in perovskite lattice. $^{22-24}$ However, reduction of $\mathrm{Pt}$ ion in $\mathrm{H}_{2}$ and easy reoxidation in $\mathrm{O}_{2}$ have been shown by XPS study earlier. ${ }^{12}$

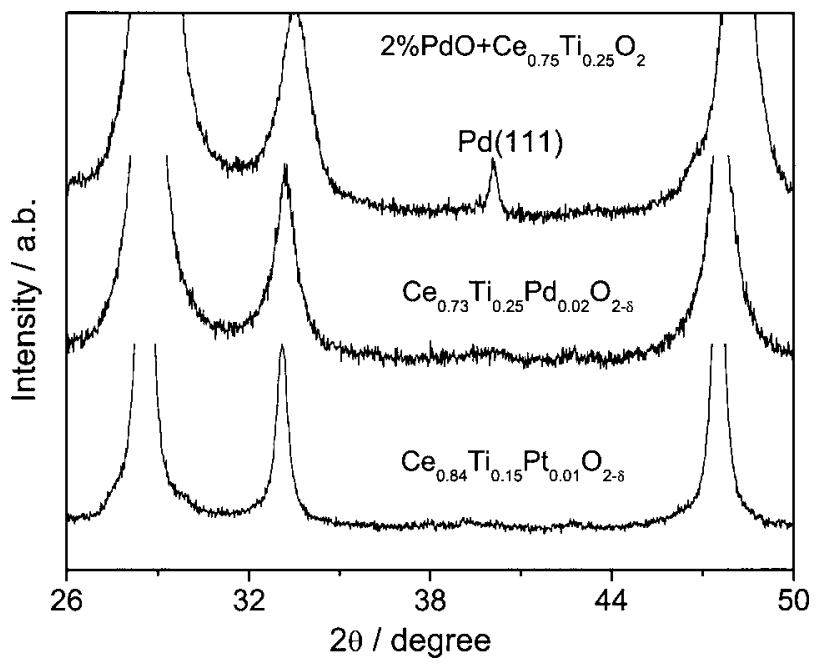

FIG. 2. XRD pattern of 1 at. $\% \mathrm{Pt} / \mathrm{Ce}_{0.85} \mathrm{Ti}_{0.15} \mathrm{O}_{2}$ (at $300{ }^{\circ} \mathrm{C}$ ), 2 at. $\%$ $\mathrm{Pd} / \mathrm{Ce}_{0.75} \mathrm{Ti}_{0.25} \mathrm{O}_{2}\left(\right.$ at $500{ }^{\circ} \mathrm{C}$ ), and $2 \% \mathrm{PdO}+\mathrm{Ce}_{0.75} \mathrm{Ti}_{0.25} \mathrm{O}_{2}$ (at $500{ }^{\circ} \mathrm{C}$ ) reduced in $5 \% \mathrm{H}_{2}+95 \%$ Ar gas. 

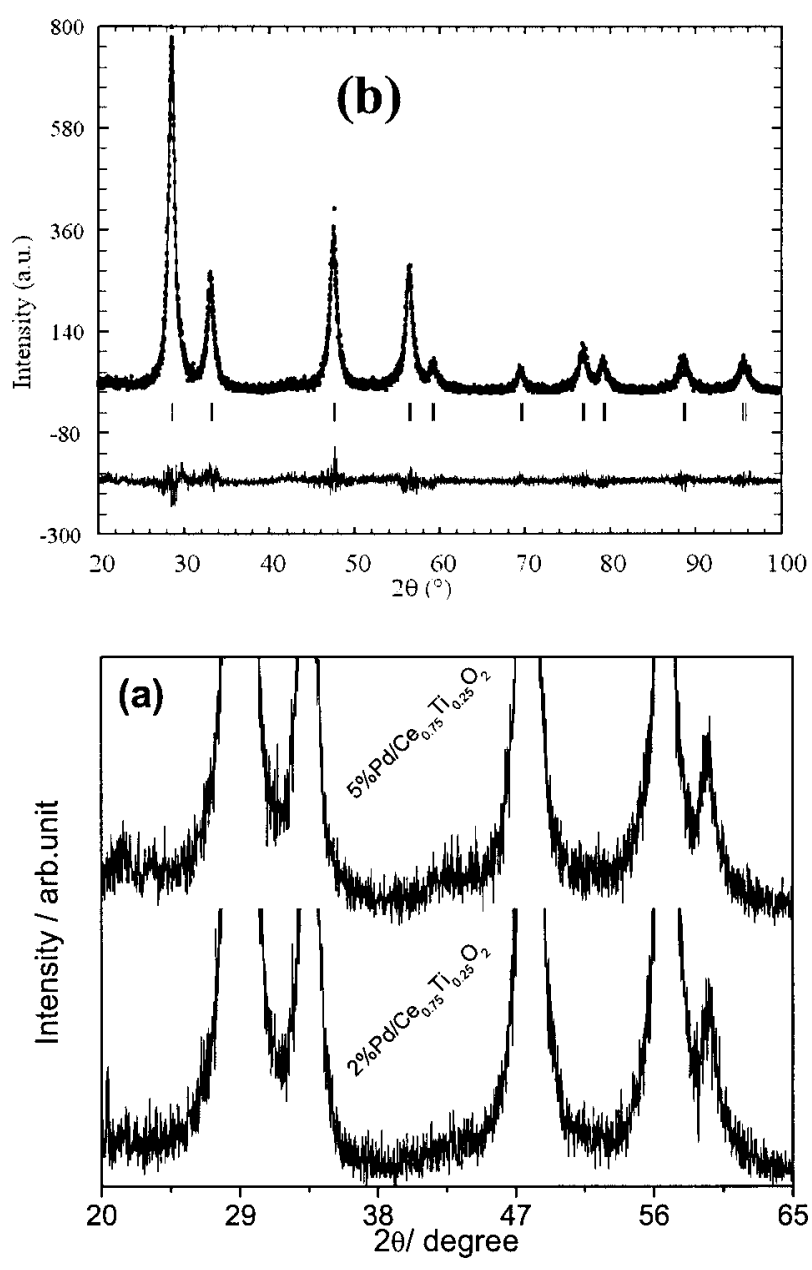

FIG. 3. (a) Ten times enlarged XRD pattern of 2 and (b) 5 at. $\%$ $\mathrm{Pd} / \mathrm{Ce}_{0.75} \mathrm{Ti}_{0.25} \mathrm{O}_{2}$.

Figure 3(a) shows the XRD pattern of as-prepared 2 and 5 at. $\% \mathrm{Pd} / \mathrm{Ce}_{0.75} \mathrm{Ti}_{0.25} \mathrm{O}_{2}$ which is ten times enlarged in the $Y$ scale. The patterns show fluorite phase of the catalysts. No intensity peak due to $\mathrm{Pd}$ metal particle or PdO can be observed. Figure 3(b) shows the Rietveld refined XRD profile of 5 at. $\% \mathrm{Pd} / \mathrm{Ce}_{0.75} \mathrm{Ti}_{0.25} \mathrm{O}_{2} . R_{\text {Bragg }}, R$ factor, and $\chi^{2}$ values are 1.94, 2.90, and 1.44 for 2 at. $\% \mathrm{Pd} / \mathrm{Ce}_{0.75} \mathrm{Ti}_{0.25} \mathrm{O}_{2}$ and $3.57,2.36$, and 1.29 for 5 at. $\% \mathrm{Pd} / \mathrm{Ce}_{0.75} \mathrm{Ti}_{0.25} \mathrm{O}_{2}$, respectively. Lattice parameter values are, respectively, 5.3992(6) and 5.4082(5) $\AA$. The increase in lattice parameter is 5\% Pd substituted compound due to higher ionic radii of $\mathrm{Pd}^{2+}$ ion compared to smaller $\mathrm{Ti}^{4+}$ ion which gets substituted by $\mathrm{Pd}^{2+}$ ion.

Similar to Pt- substituted catalyst, in Fig. 2 the XRD pattern of $\mathrm{Ce}_{0.73} \mathrm{Ti}_{0.25} \mathrm{Pd}_{0.02} \mathrm{O}_{2-\delta}$ and 2 at. \% $\mathrm{PdO}$ $+\mathrm{Ce}_{0.75} \mathrm{Ti}_{0.25} \mathrm{O}_{2}$ (mixture) reduced in $\mathrm{H}_{2}$ is shown. $\mathrm{Pd}(111)$ metal peak at $2 \theta=40.2$ is not observed in the substituted catalyst whereas the same gives a prominent peak in 2 at. \% $\mathrm{PdO}+\mathrm{Ce}_{0.75} \mathrm{Ti}_{0.25} \mathrm{O}_{2}$.

\section{XPS study}

The valence state of platinum species in the $\mathrm{Ce}_{1-x} \mathrm{Ti}_{x} \mathrm{O}_{2}$ support was determined by XPS of $\operatorname{Pt}(4 f)$ core level spectra. $\operatorname{Pt}(4 f)$ core level region in pt metal foil and as-prepared 1 at. $\% \mathrm{Pt} / \mathrm{Ce}_{0.85} \mathrm{Ti}_{0.15} \mathrm{O}_{2}$ is given in Fig. 4 . $\mathrm{Pt}^{0}$ in $\mathrm{Pt}$ metal
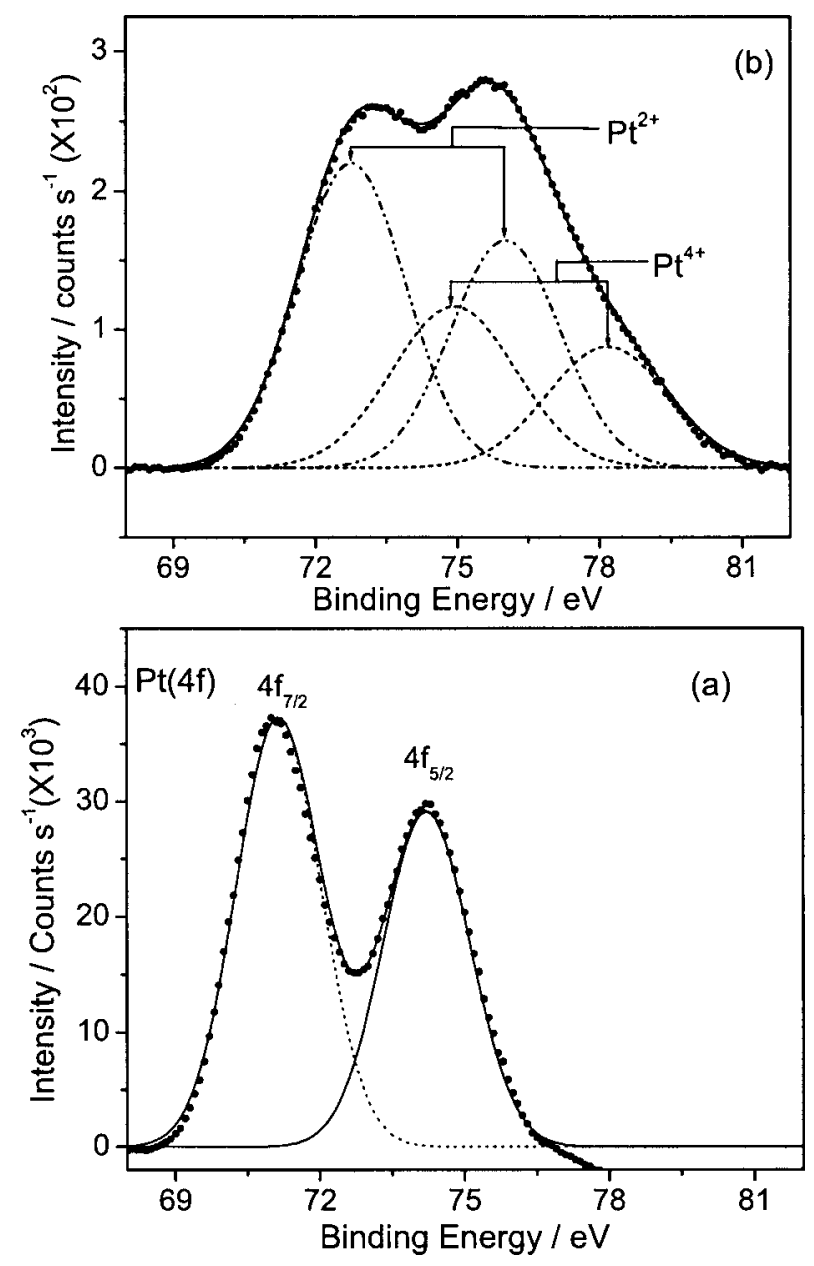

FIG. 4. $\mathrm{Pt}(4 f)$ core level spectra in (a) Pt metal foil and (b) 1 at. \% $\mathrm{Pt} / \mathrm{Ce}_{0.85} \mathrm{Ti}_{0.15} \mathrm{O}_{2}$.

particles shows $4 f_{7 / 2,5 / 2}$ at 71.1 and $74.3 \mathrm{eV}$, respectively [Fig. 4(a)]. However, Pt spectra are very broad in the oxide support. Therefore, $\operatorname{Pt}(4 f)$ spectrum was deconvoluted into sets of spin-orbit doublets for different oxidation states of Pt. In $1 \% \mathrm{Pt} / \mathrm{Ce}_{0.85} \mathrm{Ti}_{0.15} \mathrm{O}_{2}$, the $\mathrm{Pt}(4 f)$ region [Fig. 4(b)] was deconvoluted into two sets of spin-orbit doublets because significant intensity due to metallic platinum was not observed even after ten times magnification in XRD. Accordingly, the peaks at $72.8,76$ and $75,78.2 \mathrm{eV}$ are attributed to

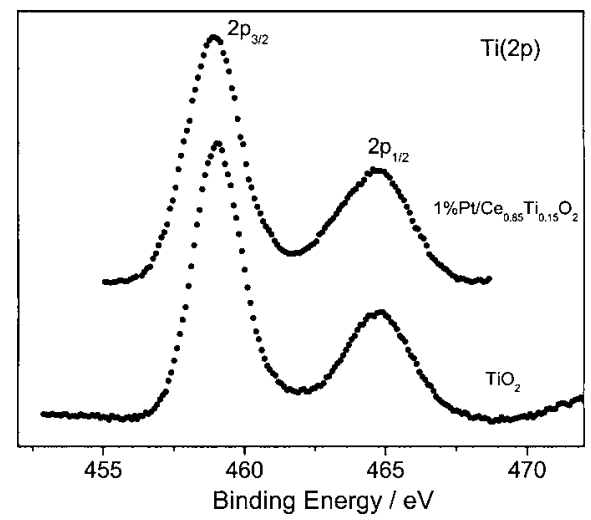

FIG. 5. $\mathrm{Ti}(2 p)$ core level spectra in (a) $\mathrm{TiO}_{2}$ and (b) 1 at. $\%$ $\mathrm{Pt} / \mathrm{Ce}_{0.85} \mathrm{Ti}_{0.15} \mathrm{O}_{2}$. 


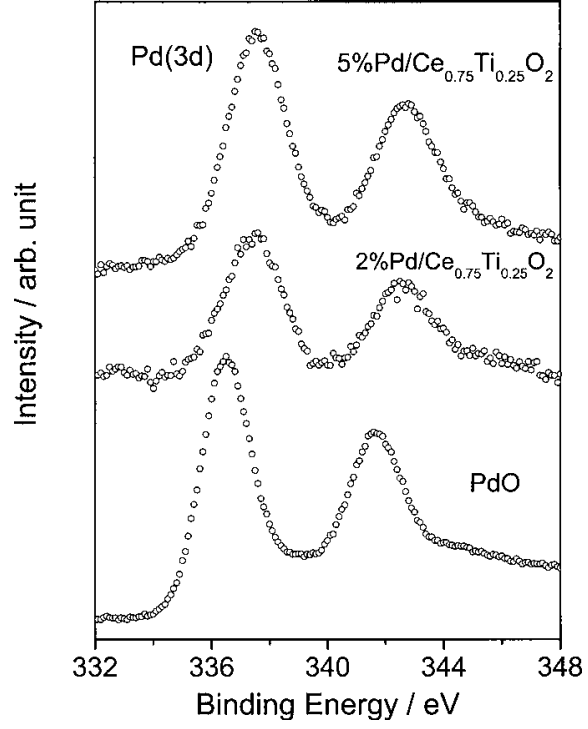

FIG. 6. $\mathrm{Pd}(3 d)$ core level spectra in $\mathrm{PdO}, 2$ at. $\% \mathrm{Pd} / \mathrm{Ce}_{0.75} \mathrm{Ti}_{0.25} \mathrm{O}_{2}$, and 5 at. $\% \mathrm{Pd} / \mathrm{Ce}_{0.75} \mathrm{Ti}_{0.25} \mathrm{O}_{2}$.

Pt in +2 and +4 oxidation states, respectively. About $\sim 65 \%$ $\mathrm{Pt}$ are in +2 state and the rest is in +4 state in 1 at. \% $\mathrm{Pt} / \mathrm{Pt}_{0.85} \mathrm{Ti}_{0.15} \mathrm{O}_{2-\delta}$.

The $\mathrm{Ti}(2 p)$ spectrum of pure $\mathrm{TiO}_{2}$ and as-prepared 1 at. $\% \mathrm{Pt} / \mathrm{Ce}_{0.85} \mathrm{Ti}_{0.15} \mathrm{O}_{2}$ is shown in Fig. 5. Binding energies of $\mathrm{Ti}\left(2 p_{3 / 2,1 / 2}\right)$ at 459.0 and $464.8 \mathrm{eV}$ in $\mathrm{TiO}_{2}$ correspond to $\mathrm{Ti}$ in $4+$ state [Fig. $5(\mathrm{a})]$. The $\mathrm{Ti}\left(2 p_{3 / 2,1 / 2}\right)$ peaks in as-prepared 1 at. $\% \mathrm{Pt} / \mathrm{Ce}_{0.85} \mathrm{Ti}_{0.15} \mathrm{O}_{2}$ are observed at 458.8 and $464.7 \mathrm{eV}$ [Fig. 5(b)] and therefore, Ti is essentially in 4+ state in the Pt-substituted catalysts. Similarly, $\mathrm{Ce}$ is also present in the 4+ state in all the compounds.

Figure 6 shows the $\mathrm{Pd}(3 d)$ core level spectra in $\mathrm{PdO}$, as-prepared 2 and 5 at. $\% \mathrm{Pd} / \mathrm{Ce}_{0.75} \mathrm{Ti}_{0.25} \mathrm{O}_{2}$. The binding
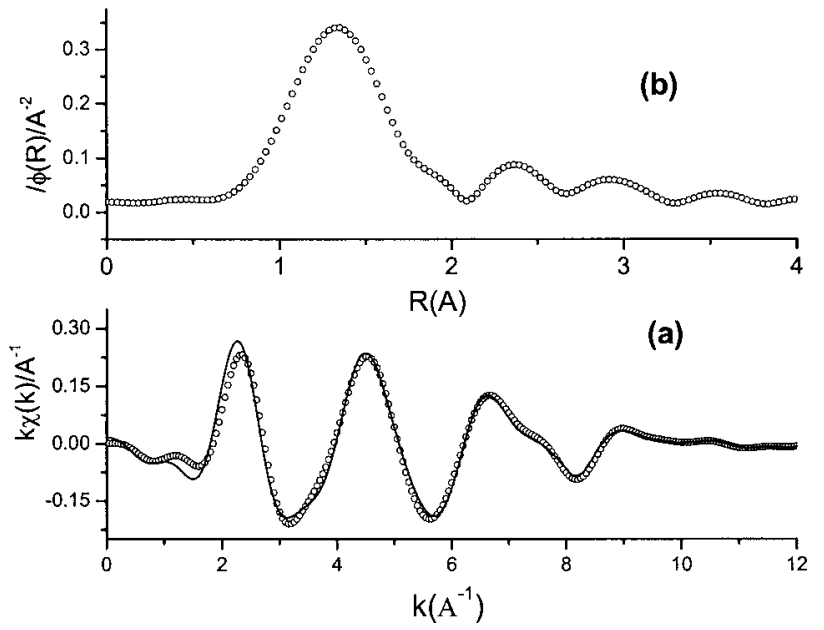

FIG. 7. (a) Fourier transformed EXAFS spectra at the Ti $K$ edge in 1 at. $\%$ $\mathrm{Pt} / \mathrm{Ce}_{0.85} \mathrm{Ti}_{0.15} \mathrm{O}_{2}$ and (b) magnitude of $k^{2}$ weighted EXAFS spectra in 1 and 2 at. $\% \mathrm{Pt} / \mathrm{Ce}_{0.85} \mathrm{Ti}_{0.15} \mathrm{O}_{2}$.

energy of $\mathrm{Pd}\left(3 d_{5 / 2}\right)$ in $\mathrm{PdO}$ is $336.4 \mathrm{eV}$ corresponding to 2 + state. $\operatorname{Pd}\left(3 d_{5 / 2}\right)$ is observed at $337.7 \mathrm{eV}$ in as-prepared 2 and 5 at. $\% \mathrm{Pd} / \mathrm{Ce}_{0.75} \mathrm{Ti}_{0.25} \mathrm{O}_{2} . \quad \mathrm{PdCl}_{2}$ is observed at $338.0 \mathrm{eV}^{25}$ Therefore, $\mathrm{Pd}$ ion is in +2 state, but it is more ionic in $\mathrm{Ce}_{0.75} \mathrm{Ti}_{0.25} \mathrm{O}_{2}$ than in PdO. Similarly, both Ti and $\mathrm{Ce}$ ions showing similar spectra are found to be in 4+ state.

\section{EXAFS study}

The $k^{2}$ weighted Fourier transform $(\mathrm{FT})$ of Ti $K$-edge EXAFS in $1 \% \mathrm{Pt} / \mathrm{Ce}_{0.85} \mathrm{Ti}_{0.15} \mathrm{O}_{2}$ is presented in Fig. 7(a). These spectra are very similar to those of Ti EXAFS in $\mathrm{Ce}_{1-x} \mathrm{Ti}_{x} \mathrm{O}_{2}$ solid solutions ${ }^{13}$ where we had reported that the oxygen coordination around $\mathrm{Ti}$ is distorted in these solid solutions. From experimental data analysis as well as first prin-

TABLE I. EXAFS analysis in Pt/CeTiO 2 at Ti $K$ edge and $\mathrm{Pt} L_{\mathrm{III}}$ edge.

\begin{tabular}{|c|c|c|c|c|}
\hline Sample & Coordination shell & $\mathrm{CN}$ & $R$ & $\sigma^{2}$ \\
\hline \multicolumn{5}{|c|}{ Ti $K$ edge } \\
\hline \multirow{4}{*}{$1 \% \mathrm{Pt} / \mathrm{Ce}_{0.85} \mathrm{Ti}_{0.15} \mathrm{O}_{2}$} & Ti-O & 4 & $1.897 \pm 0.06$ & $0.005 \pm 0.001$ \\
\hline & & 4 & $2.50 \pm 0.02$ & $0.023 \pm 0.006$ \\
\hline & $\mathrm{Ti}-\mathrm{Ti}$ & 1.8 & $2.98 \pm 0.03$ & $0.010 \pm 0.004$ \\
\hline & $\mathrm{Ti}-\mathrm{Ce}$ & 10.2 & $3.52 \pm 0.06$ & $0.03 \pm 0.01$ \\
\hline \multicolumn{5}{|c|}{ Pt $L_{\mathrm{III}}$ edge } \\
\hline \multirow{5}{*}{$1 \% \mathrm{Pt} / \mathrm{Ce}_{0.85} \mathrm{Ti}_{0.15} \mathrm{O}_{2}$} & $\mathrm{Pt}-\mathrm{O}$ & $2.9 \pm 0.1$ & $0.004 \pm 0.003$ & $0.0049 \pm 0.0004$ \\
\hline & & $3.9 \pm 0.1$ & $2.63 \pm 0.04$ & $0.041 \pm 0.009$ \\
\hline & $\mathrm{Pt}-\mathrm{Pt}$ & $3.6 \pm 0.6$ & $2.768 \pm 0.002$ & $0.0049 \pm 0.0002$ \\
\hline & $\mathrm{Pt}-\mathrm{Ti}$ & $1.1 \pm 0.3$ & $3.12 \pm 0.02$ & $0.016 \pm 0.003$ \\
\hline & $\mathrm{Pt}-\mathrm{Ce}$ & $5.1 \pm 0.7$ & $3.54 \pm 0.01$ & $0.020 \pm 0.002$ \\
\hline \multirow[t]{4}{*}{ PT } & $\mathrm{Pt}-\mathrm{Pt}$ & 12.0 & $2.762 \pm 0.004$ & $0.009 \pm 0.001$ \\
\hline & & 6.0 & $3.901 \pm 0.005$ & $0.013 \pm 0.003$ \\
\hline & & 48.0 & $4.138 \pm 0.005$ & $0.016 \pm 0.003$ \\
\hline & & 24.0 & $4.778 \pm 0.006$ & $0.015 \pm 0.002$ \\
\hline \multirow[t]{4}{*}{$\mathrm{PtO}_{2}$} & $\mathrm{Pt}-\mathrm{O}$ & $5.6 \pm 0.2$ & $1.989 \pm 0.004$ & $0.002 \pm 0.001$ \\
\hline & $\mathrm{Pt}-\mathrm{Pt}$ & $3.7 \pm 0.2$ & $3.153 \pm 0.002$ & $0.006 \pm 0.001$ \\
\hline & $\mathrm{Pt}-\mathrm{Pt}$ & $7.6 \pm 0.4$ & $3.556 \pm 0.006$ & $0.014 \pm 0.008$ \\
\hline & $\mathrm{Pt}-\mathrm{O}$ & $4.5 \pm 0.6$ & $3.695 \pm 0.006$ & $0.005 \pm 0.002$ \\
\hline
\end{tabular}



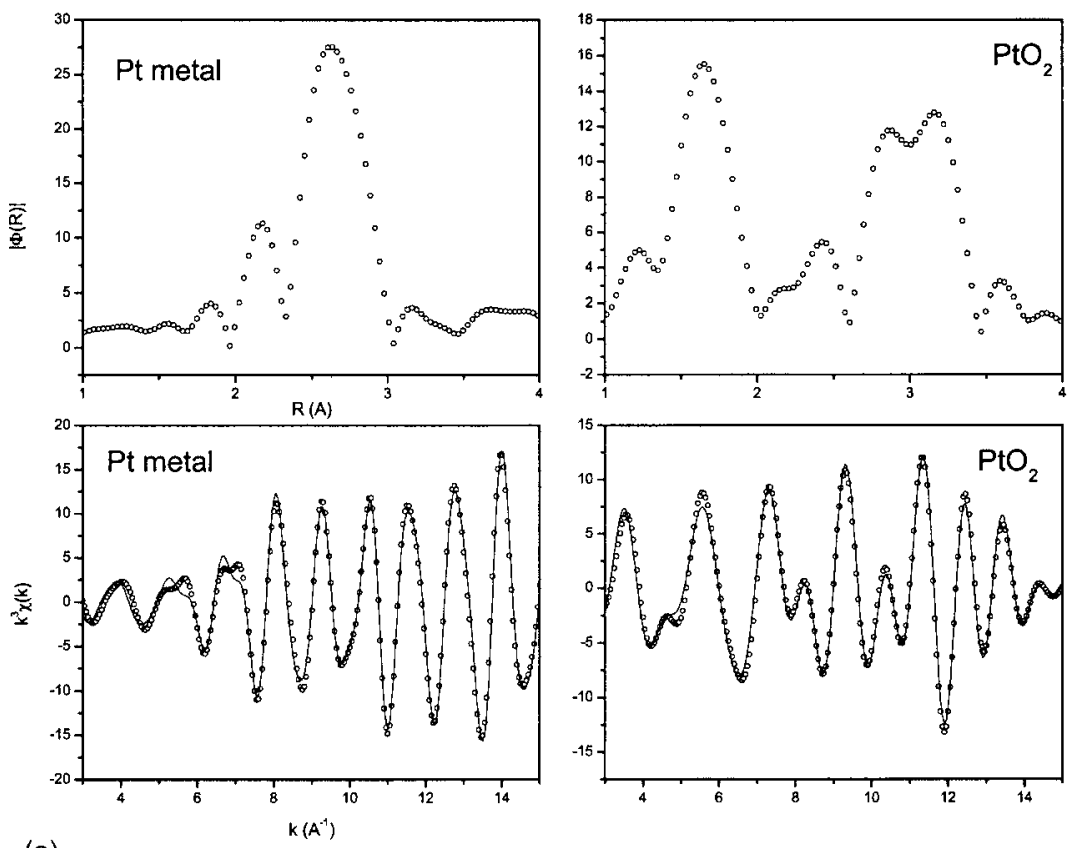

(a)

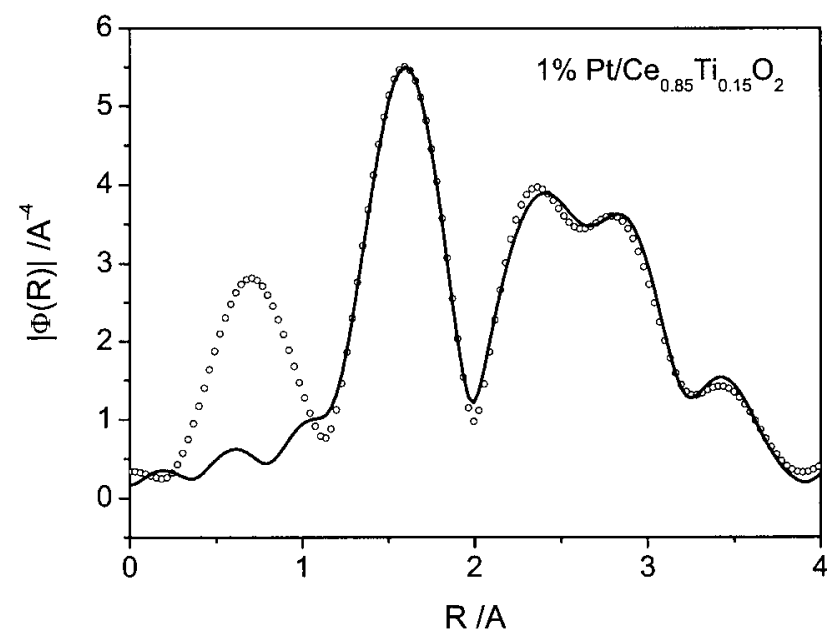

FIG. 8. (a) Magnitude of FT and corresponding backtransforms of $\mathrm{Pt} L_{\mathrm{III}}$ edge in $\mathrm{Pt}$ metal foil and $\mathrm{PtO}_{2}$ and (b) backtransformed $k^{3}$ weighted EXAFS with fit and magnitude of FT of Pt $L_{\mathrm{III}}$ edge in 1 at. $\% \mathrm{Pt} / \mathrm{Ce}_{0.85} \mathrm{Ti}_{0.15} \mathrm{O}_{2}$.

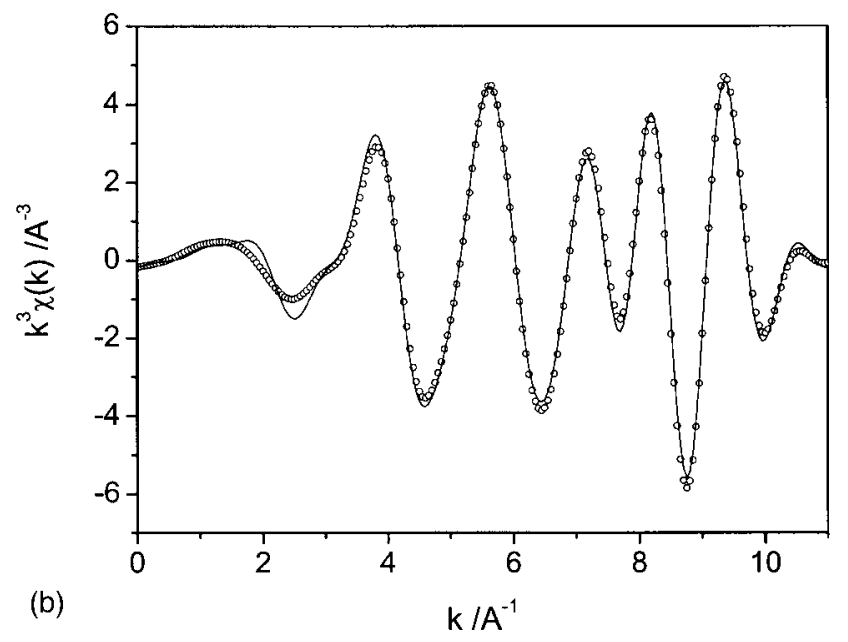

cipal theoretical calculations it was found that of the eight O's surrounding the metal ion in fluorite structure, four come closer and four move away. The weighted EXAFS data in the $k$ range $2-10 \AA^{-1}$ were transformed to $R$ space and was fitted to the same $4+4$ coordination model using Ti-O correlations and $\mathrm{Ti}-\mathrm{Ti}$ and $\mathrm{Ti}-\mathrm{Ce}$ coordination shells. The re- sultant backtransformed data along with the fit are presented in Fig. 7(b). The values of bond lengths and Debye-Waller terms are presented in Table I. When coordination was taken as $8,6+2$ or $4+2+2$ fitting was poor.

Figure 8 (a) shows the $k^{3}$ weighted FT of the Pt $L_{\text {III }}$ EXAFS spectra of $\mathrm{Pt}$ metal and $\mathrm{PtO}_{2}$ along with their inverse 
(a)

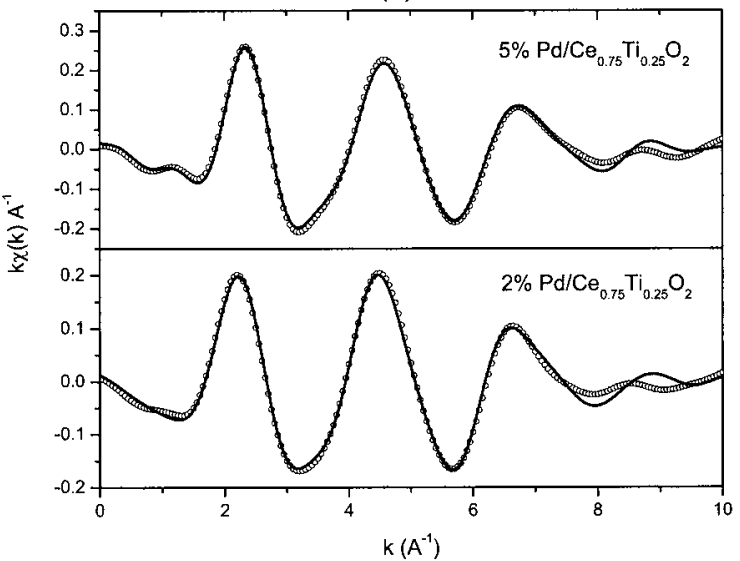

(b)

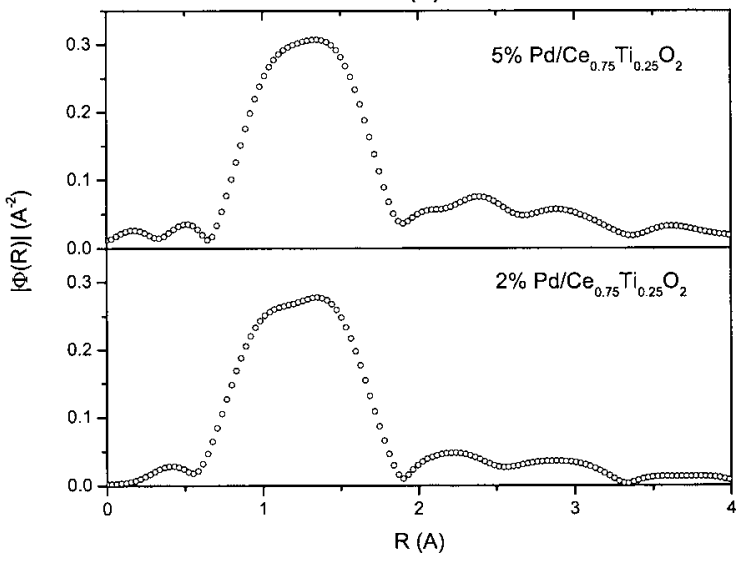

FIG. 9. (a) Fourier transformed EXAFS spectra at the Ti $K$ edge in 2 and 5 at. $\% \mathrm{Pd} / \mathrm{Ce}_{0.75} \mathrm{Ti}_{0.25} \mathrm{O}_{2}$ and (b) magnitude of $k^{2}$ weighted EXAFS spectra in 1 and 2 at. $\% \mathrm{Pt} / \mathrm{Ce}_{0.85} \mathrm{Ti}_{0.15} \mathrm{O}_{2}$.

transforms. The Fourier transforms are not corrected for phase shift and hence the peaks are shifted to lower $R$ values. However, as mentioned above, the values of bond distance quoted in the text and table are corrected for phase shift. For Pt metal foil, the Pt-Pt scattering peak is seen at $2.76 \AA$. In addition to it, a small peak on the lower $R$ side of the main peak can be seen. This is caused by both the $k$-dependent behavior of backscattering amplitude and nonlinearly in the phase shift function. $\mathrm{Pt}-\mathrm{O}$ correlation in $\mathrm{PtO}_{2}$ appears at about $1.99 \AA$ and a Pt-Pt correlation is observed at an average distance of $3.15 \AA$. The values of bond distance, coordination number, and Debye-Waller factors obtained from fitting the EXAFS data in the $R$ range $1-4 \AA$ are presented in Table I. These values agree well with the structural data of $\mathrm{Pt}$ and $\mathrm{PtO}_{2}$.

In the case of $1 \% \mathrm{Pt} / \mathrm{Ce}_{0.85} \mathrm{Ti}_{0.15} \mathrm{O}_{2}$ [Fig. 8(b)], a strong peak at about $1.5 \AA$ (phase shift uncorrected) is observed which is absent in Pt metal. This correlation is attributed to the $\mathrm{Pt}-\mathrm{O}$ bond at $2.0 \AA$. Further a broad structure with at least three distinct maxima is seen in the range $2-4 \AA$. This broad structure distinctly consists of at least three correlations and it is similar to that observed in $1 \% \mathrm{Pt} / \mathrm{CeO}_{2}{ }^{26} \mathrm{But}$ there are important differences in the two spectra particularly in weighting of the doublet structure, positions of the maxima as well as in the strength of the first $\mathrm{Pt}-\mathrm{O}$ correlation at $2 \AA$. therefore, in $\mathrm{Pt} / \mathrm{CeTiO}_{2}$ catalyst although Pt could be in similar environment as that in $\mathrm{Pt} / \mathrm{CeO}_{2}$ the nature of correlations could be different. This could be due to distorted ceria-titania matrix that $\mathrm{Pt}$ finds itself in $\mathrm{Pt} / \mathrm{CeTiO}_{2}$. Therefore, to fit the EXAFS data, a model wherein Pt ion is substituted for $\mathrm{Ce} / \mathrm{Ti}$ ion in $\mathrm{Pt} / \mathrm{Ce}_{0.8} \mathrm{Ti}_{0.2} \mathrm{O}_{2}$ structure forming a solid solution of the type $\mathrm{Pt}_{0.01} \mathrm{Ce}_{0.79} \mathrm{Ti}_{0.2} \mathrm{O}_{2-\delta}$ was considered. This model gave a good fit and the fitted parameters obtained are listed in Table I. In the solid solution phase, $\mathrm{Pt}$ has $\sim 3+4$ oxygen coordination at 2.0 and $2.63 \AA$ in the catalyst. If $\mathrm{Pt}$ ions are substituted for $\mathrm{Ce}^{4+}$ sites, the first coordination around $\mathrm{Pt}$ ion will be of oxide ions. In the case of $\mathrm{Ce}_{1-x} \mathrm{Ti}_{x} \mathrm{O}_{2}$, Ce has distorted oxygen coordination around it with four oxygen ions coming closer and four moving away. Accordingly, the coordination of $\sim 7$ (4 short +3 long) for the $\mathrm{Pt}-\mathrm{O}$ bond in the catalyst can be understood to be due to substitution of $\mathrm{Pt}^{2+}$ ions for $\mathrm{Ce}^{4+}$ ions just as $\mathrm{Ti}^{4+}$ ion in $\mathrm{CeO}_{2}$ accounting for overall oxide ion vacancy. Since $65 \%$ of Pt ions is in lower oxidation state, oxide ion vacancy is expected and the observed lower coordination supports this. Further, Pt-Pt, Pt-Ti, and Pt-Ce correlation were obtained at 2.76, 3.12, and $3.53 \AA$, respectively. These correlations indicate the presence of $\mathrm{Pt}$ ion in fluorite lattice. The total coordination number obtained was about 10 which is close to that expected for $\mathrm{Pt}$ substitution for $\mathrm{Ce}$ ion in $(\mathrm{CeTi}) \mathrm{O}_{2}$ solid solution having fluorite structure. The $\mathrm{Pt}-\mathrm{Ce}$ bond distance of $3.53 \AA$ is also close to Ti-Ce distance $(3.5 \AA)$ obtained in $(\mathrm{CeTi}) \mathrm{O}_{2}$ solid solutions. However, the $\mathrm{Pt}-\mathrm{Pt}$ coordination number $(\sim 4)$ is quite large. It must be mentioned here that while fitting, the coordination numbers were essentially kept fixed to their respective concentration ratio. In the case of $\mathrm{Pt}-\mathrm{Pt}, \mathrm{Pt}-\mathrm{Ti}$, and Pt-Ce, a good fit was obtained only for a combination of 4,1 , and 5 , respectively.

The $k^{2}$ weighted FT of Ti $K$-edge EXAFS in 2 and 5 at. $\% \mathrm{Pd} / \mathrm{Ce}_{0.75} \mathrm{Ti}_{0.25} \mathrm{O}_{2}$ is presented in Fig. 9(a). This spectrum is similar to those of $\mathrm{Ti}$ EXAFS in $\mathrm{Ce}_{1-x} \mathrm{Ti}_{x} \mathrm{O}_{2}$ solid solutions. ${ }^{13}$ The weighted EXAFS data in the $k$ range 2-10 $\AA^{-1}$ were transformed to $R$ space and were fitted to the same 4+4 model using $\mathrm{Ti}-\mathrm{O}$ correlations and $\mathrm{Ti}-\mathrm{Ti}$ and Ti-Ce coordination shells. The resultant backtransformed data along with the fit are presented in Fig. 9(b). The values of bond lengths and Debye-Waller terms are presented in Table II. The second shell in the Ti-O coordination sphere is $\sim 3$. This is due to creation of oxide ion vacancy for lower valent $\mathrm{Pd}^{2+}$ ion substitution.

Figures 10(a) and 10(b) show background subtracted $k^{3}$-weighted Pd $K$ EXAFS function with fit and its magnitude in Pd metal and PdO. The EXAFS spectrum of the catalyst is similar to that of $\mathrm{PdO}$, indicating $\mathrm{Pd}$ to be in +2 state. The phase corrected values of EXAFS data are given in Table II. The FT of PdO shows three distinct peaks in the range $1-3.5 \AA$. It is known from the crystal structure data that in $\mathrm{PdO}, \mathrm{Pd}$ ion is surrounded by four $\mathrm{O}$ ions at $2.02 \AA$ and $\mathrm{Pd}$ ions at 2.67 and $3.08 \AA$ with coordination numbers 2 and 4, respectively. These shells contribute to the first two peaks while the third peak has contributions from 8 neighbored $\mathrm{Pd}-\mathrm{O}$ shell at $3.58 \AA$ and 16 neighbored $\mathrm{Pd}-\mathrm{Pd}$ shell at $3.72 \AA$. From the EXAFS data, we have shown local structure of $\mathrm{Ce}^{4+}, \mathrm{Ti}^{4+}$, and $\mathrm{Pd}^{2+}$ ions in Fig. 11. $\mathrm{Ce}^{4+}$ is found to have four $\mathrm{Ce}-\mathrm{O}$ bonds of $2.30 \AA$ and four $\mathrm{Ce}-\mathrm{O}$ of $2.42 \AA{ }^{13}$ 
TABLE II. EXAFS analysis in $\mathrm{Pd}$ metal, $\mathrm{PdO}$, and $\mathrm{Pd} / \mathrm{CeTiO}_{2}$ at $\mathrm{Ti} K$ and $\mathrm{Pd} K$ edges.

\begin{tabular}{|c|c|c|c|c|}
\hline Sample & $\begin{array}{c}\text { Coordination } \\
\text { shell }\end{array}$ & $\mathrm{CN}$ & $R$ & $\sigma^{2}$ \\
\hline & & Ti $K$ edge & & \\
\hline \multirow[t]{4}{*}{$2 \% \mathrm{Pd} / \mathrm{Ce}_{0.75} \mathrm{Ti}_{0.25} \mathrm{O}_{2}$} & Ti-O & 4 & $1.925 \pm 0.004$ & $0.007 \pm 0.001$ \\
\hline & & $2.9 \pm 0.5$ & $2.48 \pm 0.02$ & $0.032 \pm 0.006$ \\
\hline & $\mathrm{Ti}-\mathrm{Ti}$ & $2.2 \pm 0.6$ & $3.05 \pm 0.03$ & $0.019 \pm 0.005$ \\
\hline & $\mathrm{Ti}-\mathrm{Ce}$ & $9.0 \pm 0.2$ & $3.67 \pm 0.03$ & $0.038 \pm 0.006$ \\
\hline \multirow[t]{5}{*}{$5 \% \mathrm{Pd} / \mathrm{Ce}_{0.75} \mathrm{Ti}_{0.25} \mathrm{O}_{2}$} & $\mathrm{Ti}-\mathrm{O}$ & 4 & $1.903 \pm 0.004$ & $0.0064 \pm 0.0007$ \\
\hline & & $3.0 \pm 0.4$ & $2.42 \pm 0.01$ & $0.022 \pm 0.004$ \\
\hline & $\mathrm{Ti}-\mathrm{Ti}$ & $2.0 \pm 0.7$ & $3.15 \pm 0.05$ & $0.025 \pm 0.009$ \\
\hline & $\mathrm{Ti}-\mathrm{Ce}$ & $5.3 \pm 0.2$ & $3.82 \pm 0.08$ & $0.062 \pm 0.01$ \\
\hline & Ti-Pd & $1.2 \pm 0.4$ & $3.20 \pm 0.03$ & $0.010 \pm 0.001$ \\
\hline \multicolumn{5}{|c|}{ Pd $K$ edge } \\
\hline \multirow[t]{5}{*}{$2 \% \mathrm{Pd} / \mathrm{Ce}_{0.75} \mathrm{Ti}_{0.25} \mathrm{O}_{2}$} & $\mathrm{Pd}-\mathrm{O}$ & $4.0 \pm 0.02$ & $2.007 \pm 0.004$ & $0.0028 \pm 0.0004$ \\
\hline & & $3.2 \pm 0.6$ & $2.47 \pm 0.02$ & $0.013 \pm 0.003$ \\
\hline & Pd-Pd & $1.8 \pm 0.1$ & $3.059 \pm 0.005$ & $0.0048 \pm 0.0005$ \\
\hline & $\mathrm{Pd}-\mathrm{Ti}$ & $2.8 \pm 0.4$ & $2.89 \pm 0.01$ & $0.014 \pm 0.002$ \\
\hline & $\mathrm{Pd}-\mathrm{Ce}$ & $6.3 \pm 0.4$ & $3.330 \pm 0.004$ & $0.0097 \pm 0.0004$ \\
\hline \multirow[t]{4}{*}{$\mathrm{Pd}$} & $\mathrm{Pd}-\mathrm{Pd}$ & 12.0 & $2.747 \pm 0.003$ & $0.006 \pm 0.001$ \\
\hline & & 6.0 & $3.885 \pm 0.002$ & $0.009 \pm 0.001$ \\
\hline & & 48.0 & $4.120 \pm 0.002$ & $0.008 \pm 0.001$ \\
\hline & & 24.0 & $4.689 \pm 0.004$ & $0.050 \pm 0.004$ \\
\hline \multirow[t]{5}{*}{$\mathrm{PdO}$} & $\mathrm{Pd}-\mathrm{O}$ & 4.0 & $2.023 \pm 0.005$ & $0.002 \pm 0.001$ \\
\hline & Pd-Pd & 2.0 & $2.694 \pm 0.008$ & $0.011 \pm 0.003$ \\
\hline & $\mathrm{Pd}-\mathrm{Pd}$ & 4.0 & $3.079 \pm 0.009$ & $0.005 \pm 0.001$ \\
\hline & $\mathrm{Pd}-\mathrm{O}$ & 8.0 & $3.581 \pm 0.002$ & $0.002 \pm 0.001$ \\
\hline & $\mathrm{Pd}-\mathrm{O} / \mathrm{Pd}$ & 16.0 & $3.721 \pm 0.009$ & $0.006 \pm 0.001$ \\
\hline
\end{tabular}

Both $\mathrm{Ti}^{4+}$ and $\mathrm{Pd}^{2+}$ ions have $4+3$ coordination. Ti-O bond distances were 1.90 and 2.48 and $\mathrm{Pd}-\mathrm{O}$ bonds were 2.0 and $2.47 \AA$. Oxide ion vacancy is obtained in the longer coordination sphere.

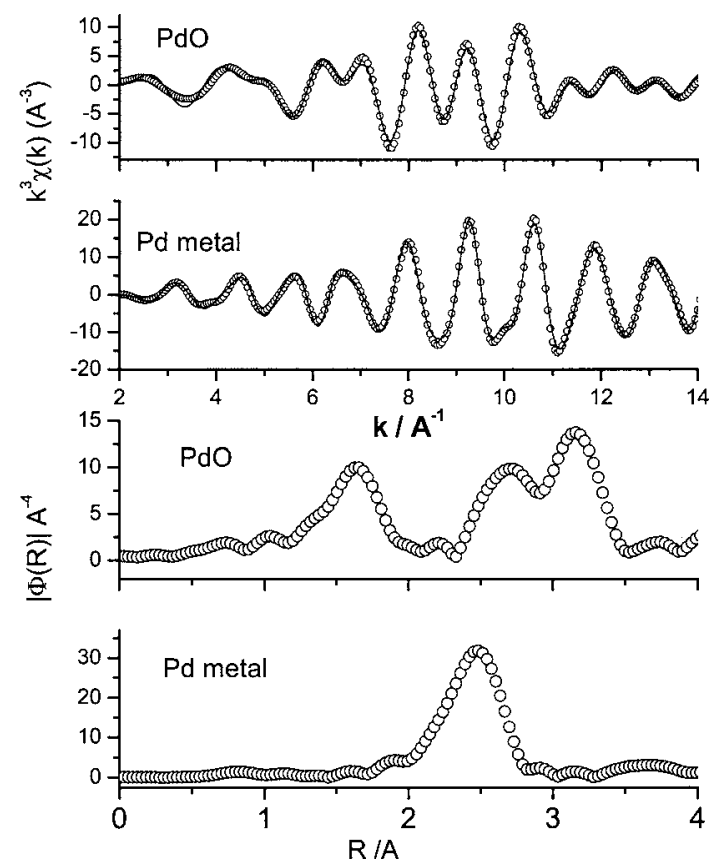

FIG. 10. Backtransform EXAFS with fit and magnitude of FT of Pd $K$ edge in $\mathrm{Pd}$ and $\mathrm{PdO}$.
In the case of catalyst sample, a strong peak at about $1.5 \AA$ (phase shift uncorrected) is seen and can be attributed to $\mathrm{Pd}-\mathrm{O}$ correlation with a bond length of $2.02 \AA$. The coordination number obtained from fitting this peak is about 4 . The fit, however, is not very good especially in the higher $R$ region where a small correlation, especially in the sample containing $5 \% \mathrm{Pd}$, can be seen. Further there is a broad structure extending from little over 2 to about $3.5 \AA$. This structure is different from the twin peak structure seen in $\mathrm{PdO}$ both in terms of peak position and relative heights, indicating the local structure around the metal ion to be different in catalyst from that in PdO. Therefore, the EXAFS was fitted to a model wherein Pd substitutes Ce ion in distorted fluorite

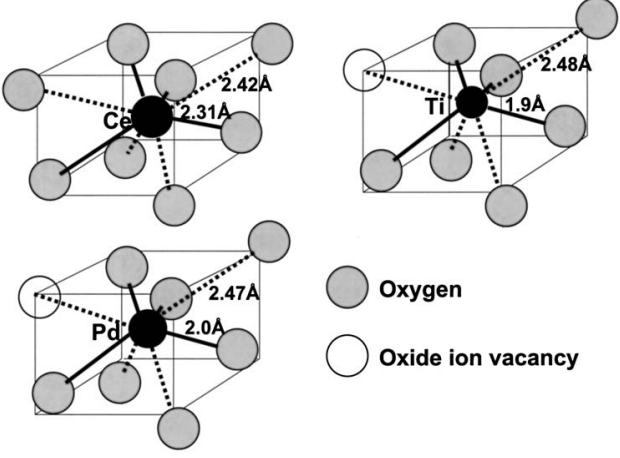

FIG. 11. Ball and stick model obtained from EXAFS fitting for the first coordination shell around $\mathrm{Ce}$, $\mathrm{Ti}$, and $\mathrm{Pd}$ ions in $\mathrm{Ce}_{0.73} \mathrm{Ti}_{0.25} \mathrm{Pd}_{0.02} \mathrm{O}_{2-\delta}$. 

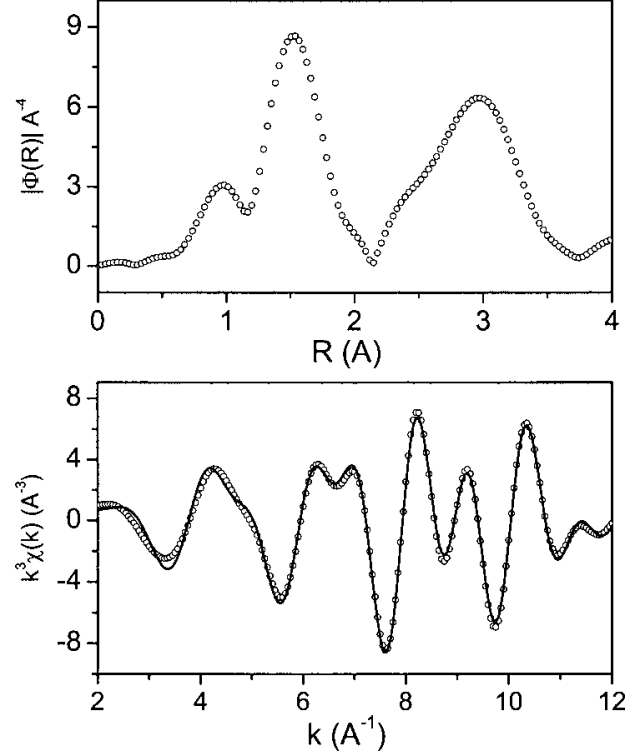

FIG. 12. Backtransform EXAFS with fit and magnitude of FT of Pd $K$ edge in $\mathrm{Ce}_{0.73} \mathrm{Ti}_{0.25} \mathrm{Pd}_{0.02} \mathrm{O}_{2-\delta}$.

structure. ${ }^{2}$ The fitting parameters obtained are presented in Table II and the fitted curves in the backtransformed $k$ space along with those of Pd metal and $\mathrm{PdO}$ are presented in Fig. 12. It can be seen that the first peak in the magnitude of FT of EXAFS spectra can be fitted with two Pd-O correlations at 2.02 and $2.47 \AA$, respectively. The total coordination number is about 7 which can be expected due to substitution of lower valent $\mathrm{Pd}^{2+}$ ion in place of $\mathrm{Ce}^{4+}$ ion. Further, the twin peak structure can be fitted with three correlations, Pd-Ti, $\mathrm{Pd}-\mathrm{Pd}$, and $\mathrm{Pd}-\mathrm{Ce}$ at 2.89, 3.06, and $3.3 \AA$, respectively. The obtained coordination numbers are also in accordance with atomic concentration of each of these ions as well as the total coordination number is close to 12 , which is expected for second coordination in fluorite structure. This clearly confirms that in $2 \% \mathrm{Pd} / \mathrm{CeTiO}_{2} \mathrm{Pd}^{2+}$ ion substitutes $\mathrm{Ce}^{4+}$ in a distorted fluorite structure.

\section{CONCLUSIONS}

$\mathrm{Pt}$ is present in the +2 and +4 ionic state in $\mathrm{Ce}_{1-x} \mathrm{Ti}_{x} \mathrm{O}_{2}$, whereas $\mathrm{Pd}$ in +2 state.

Coordination number as well as $\mathrm{Pt}-\mathrm{O}$ and $\mathrm{Pt}-\mathrm{Pt}$ or $\mathrm{Pt}-\mathrm{Ce} / \mathrm{Ti}$ distances in $\mathrm{Pt} / \mathrm{Ce}_{0.85} \mathrm{Ti}_{0.15} \mathrm{O}_{2}$ are different from those distances in $\mathrm{Pt}$ metal or $\mathrm{PtO}_{2}$. Similarly, $\mathrm{Pd}$ substitution gives different bond distances in $\mathrm{Ce}_{0.75} \mathrm{Ti}_{0.25} \mathrm{O}_{2}$.

1 at. \% $\mathrm{Pt} / \mathrm{Ce}_{0.85} \mathrm{Ti}_{0.15} \mathrm{O}_{2}$ can be written as $\mathrm{Ce}_{0.84} \mathrm{Ti}_{0.15} \mathrm{Pt}_{0.01} \mathrm{O}_{2-\delta}$ with cubic fluorite structure. Similarly, 2 and 5 at. $\% \mathrm{Pt} / \mathrm{Ce}_{0.75} \mathrm{Ti}_{0.25} \mathrm{O}_{2}$ can be written as $\mathrm{Ce}_{0.73} \mathrm{Ti}_{0.25} \mathrm{Pd}_{0.02} \mathrm{O}_{2-\delta}$ and $\mathrm{Ce}_{0.7} \mathrm{Ti}_{0.25} \mathrm{Pt}_{0.05} \mathrm{O}_{2-\delta}$, respectively.

\section{ACKNOWLEDGMENTS}

The authors from IISc and Goa University gratefully acknowledge financial support from the Department of Science and Technology, Government of India. K.R.P. and P.R.S. thank Grant-in-Aid for Scientific Research Category S. No. 16106010 for financial support to carry out EXAFS experiments and PF Advisory Committee (PAC) Approval for approval of the project. P.R.S. would like to thank Hokkaido University for a Visiting Professorship.

${ }^{1}$ P. Bera, K. C. Patil, V. Jayaram, G. N. Subbanna, and M. S. Hegde, J. Catal. 196, 293 (2000).

${ }^{2}$ K. R. Priolkar, P. Bera, P. R. Sarode, M. S. Hegde, S. Emura, R. Kumashiro, and N. P. Lalla, Chem. Mater. 14, 2120 (2002).

${ }^{3}$ P. Bera, K. R. Priolkar, P. R. Sarode, M. S. Hegde, S. Emura, R. Kumashiro, V. Jayaram, and N. P. Lalla, Chem. Mater. 14, 3591 (2002).

${ }^{4}$ P. Bera, K. R. Priolkar, A. Gayen, P. R. Sarode, M. S. Hegde, S. Emura, R. Kumashiro, V. Jayaram, and G. N. Subbanna, Chem. Mater. 15, 2049 (2003).

${ }^{5}$ A. Gayen, K. R. Priolkar, P. R. Sarode, V. Jayaram, M. S. Hedge, G. N. Subbanna, and S. Emura, Chem. Mater. 16, 2317 (2004).

${ }^{6}$ P. Bera, A. Gayen, M. S. Hegde, N. Lalla, L. Spadaro, F. Frusteri, and F. Arena, J. Phys. Chem. B 107, 6122 (2003).

${ }^{7}$ Catalysis by Ceria and Related Materials, edited by A. Trovarelli (Imperial College Press, London, 2002).

${ }^{8}$ E. Mamontov, T. Egami, R. Brezny, M. Koranne, and S. Tyagi, J. Phys. Chem. B 104, 11110 (2000).

${ }^{9}$ P. Fornasiero, G. Balducci, R. De Monte, J. Kaspar, V. Sergo, G. Gubitosa, A. Ferrero, and M. Graziani, J. Catal. 164, 173 (1996).

${ }^{10}$ P. Fornasiero, E. Fonda, R. De Monte, G. Vlaic, J. Kašpar, and M. Graziani, J. Catal. 177, 187 (1999).

${ }^{11}$ E. Bekyarova, P. Fernasiero, J. Kašpar, and M. Graziani, Catal. Today 45, 179 (1998).

${ }^{12}$ T. Baidya, A. Gayen, M. S. Hegde, N. Ravishankar, and L. Dupont, J. Phys. Chem. B 110, 5262 (2006).

${ }^{13}$ G. Dutta, U. V. Waghmare, T. Baidya, M. S. Hedge, K. R. Priolkar, and P. R. Sarode, Chem. Mater. 18, 3249 (2006).

${ }^{14}$ T. Baidya, A. Marimuthu, M. S. Hegde, N. Ravishankar, and G. Madras, J. Phys. Chem. C 111, 830 (2007).

${ }^{15}$ R. A. Young, The Rietveld Method (Oxford University Press, New York, 1995).

${ }^{16}$ M. Nomura and A. Koyama, Nucl. Instrum. Methods Phys. Res. A 467468, 733 (2001).

${ }^{17}$ M. Nomura, Y. Koike, M. Sato, A. Koyama, Y. Inada, and K. Asakura, AIP Conf. Proc. 882, 896 (2007).

${ }^{18}$ E. A. Stern and K. Kim, Phys. Rev. B 23, 3781 (1981).

${ }^{19}$ W. P. Pearson, Handbook of Lattice Spacing and Structure of Metals and Alloys (Pergamon, New York, 1958).

${ }^{20}$ S. I. Zabinsky, J. J. Rehr, A. Ankudinov, R. C. Albers, and M. J. Eller, Phys. Rev. B 52, 2996 (1995).

${ }^{21}$ E. A. Stern, M. Newville, B. Ravel, Y. Yacoby, and D. Haskel, Physica B 208-209, 117 (1995).

${ }^{22}$ Y. Nishihata, J. Mizuki, T. Akao, H. Tanaka, M. Uenishi, M. Kimura, T. Okamoto, and N. Hamada, Nature (London) 418, 164 (2002).

${ }^{23}$ H. Tanaka, M. Taniguchi, M. Uenishi, N. Kajita, I. Tan, and Y. Nishihata, Angew. Chem., Int. Ed. 45, 5998 (2006).

${ }^{24}$ J. Li, U. G. Singh, J. W. Bennett, K. Page, J. C. Weaver, Z.-P. Zhang, T. Proffen, A. M. Rappe, S. Scott, and R. Seshadri, Chem. Mater. 19, 1418 (2007).

${ }^{25}$ D. Briggs and M. P. Seah, Practical Surface Analysis (Wiley, New York, 2004).

${ }^{26}$ P. Bera, K. R. Priolkar, A. Gayen, P. R. Sarode, M. S. Hegde, S. Emura, R. Kumashiro, V. Jayaram, and G. N. Subbanna, Chem. Mater. 14, 3591 (2002). 